\title{
MORBIDADE NA CRIANÇA E LESÕES IRREVERSÍVEIS OCASIONADAS POR MATERIAL DE LIMPEZA
}

\author{
Sarah Anna Macieira* \\ Hellen Carla Rickli
}

\begin{abstract}
RESUMO. O presente trabalho tem como objetivo relatar um estudo de caso desenvolvido com uma criança desnutrida, de 6 anos, do sexo feminino, com estenose de esôfago. Como estratégia metodológica realizamos a coleta de dados através de estudo em prontuário médico e visita domiciliar. Observamos a falta de percepção da família sobre os riscos dos produtos de limpeza ao alcance da criança; a necessidade de acompanhamento da equipe de saúde (enfermeiro, psicólogo, médico, assistente social e nutricionista), cobrando da mãe cuidados específicos de nutrição, cuidados com a gastrostomia, medicação, prevenção de acidentes domésticos, e orientando-a como guardar material de limpeza.
\end{abstract}

Palavras-chave: estenose de esôfago, gastrostomia, pediatria.

\section{CHILDREN MORBIDITY AND IRREVERSIBLE INJURY CAUSED BY CLEANING MATERIAL}

\begin{abstract}
The purpose of the present work is to report a case study on a malnourished 6 year old suffering from esophagus stenosis. As a methodological strategy data collection was performed through studies of medical charts and house visits. It was observed a lack of perception by the family regarding the dangers of having cleaning products within the reach of the child. The necessity of attendance of the health team (nurse, psychologist, doctor, social worker and nutritionist), guiding the mother with respect to special care with nutrition, care with the gastrotomy, medication, and domestic accident prevention, with advice on how to keep cleaning material.
\end{abstract}

Key words: esophagus stenosis, gastrostomy, pediatrics.

\section{INTRODUÇÃO}

As intoxicações são muito freqüentes em crianças com idade de 2 para 3 anos, e são causadas principalmente por produtos domésticos deixados por adultos em lugares acessíveis às crianças (Schvartsman, 1978). Santos Filho e Araujo (1997) relatam que a maior parte dos acidentes com agentes tóxicos ocorre por ingestão acidental, antes dos 5 anos.

De acordo com o Centro de Controle de Intoxicações (CCI) do Hospital Universitário de Maringá (HUM), que atendeu a um total de 2.548 casos de intoxicações em 1997, 93 foram causados por produto químico industrial e 121 por domissanitários (Universidade Estadual de Maringá, 1998). Estes dados demonstram a importância de se prevenirem intoxicações por estas causas, visto que as crianças são as mais acometidas por este tipo de acidente, tendo, como conseqüência, seqüelas graves.

A ingestão de produtos cáusticos, embora freqüente, não se constitui como emergência clínica, e sim endoscópica. Os ácidos produzem necrose de coagulação, e o coágulo formado diminui a probabilidade de aprofundamento da lesão. Logo após a ingestão surge dor intensa, com queimação na boca, na garganta, na gengiva e retro-esternal, com espasmo reflexo da glote, o que impede a entrada de maior quantidade do cáustico ingerido mas também pode levar à morte por asfixia. Segundo Santos Filho e Araujo, "as lesões provocadas no esôfago e estômago por ingestão de cáusticos habitualmente são

* Docente do Departamento de Enfermagem da Universidade Estadual de Maringá.

\# Enfermeira da Unidade Coronária do Hospital e Maternidade Santa Rita - Maringá/PR.

Endereço para correspondência: Universidade Estadual de Maringá, Departamento de Enfermagem. Av. Colombo, 5790, Maringá-Pr. CEP - 87020-900. Tel: (0xx44) 261-4318 ou (0xx44) 261-4385. E-mail: samacieira@uem.br 
devastadoras e progressivas" (1997). Após a recuperação é possível o surgimento de estenose cicatricial do esôfago (Schvartsman, 1991).

Os ácidos corroem o tecido vivo por queimar a mucosa do tubo digestivo (Brito Filho, 1988). A estenose se forma com a progressiva deposição de colágeno "e consiste na retração circunferencial e longitudinal do tecido cicatrizado", o que impossibilita ao paciente a ingestão via oral de alimentos sólidos, líquidos ou da própria saliva. O diagnóstico precoce é feito através de endoscopia, e o raio-x de tórax é útil para diagnosticar pneumonias e perfurações gástricas/esofágicas. Broto e cols. (1998) estudaram, durante 22 anos, 1296 casos de ingestão de cáusticos em crianças, e afirmam que o tratamento se baseou em dilatações esofágicas.

Após o atendimento de emergência, a conduta deve visar manter o estado nutricional. Sabe-se que a ingesta calórica inadequada prejudica o processo de cicatrização e aumenta a suscetibilidade a infecções, uma vez que "o trato gastrintestinal desempenha papel importante nos mecanismos de defesa imunológica" (Leite, 1999).

Assim, a nutrição enteral deve fornecer o suporte nutricional e metabólico necessário. Entende-se por nutrição enteral a administração de nutrientes via oral, sonda ou ostomia, devendo sempre ser feita na presença ou em risco de desnutrição, quando a via oral for insuficiente para evitar a perda de peso ou quando o paciente não se encontra com a integridade preservada.

As crianças estão em constante crescimento e desenvolvimento, necessitando, assim, de um maior aporte de nutrientes, em proporção ao peso, em relação aos adultos; elas correm o risco de desnutrição quando ficam por tempo prolongado sem apetite, quando aceitam um número reduzido de alimentos (Menendez, Elias \& Ito, 1999) ou quando se encontram doentes, devendo ser administrada nutrição enteral o mais rapidamente possível. Como peso e estatura constituem os índices mais importantes na avaliação do crescimento, a criança deve ter um constante acompanhamento destas medidas.

Durante a idade de 4 a 10 anos, as quantidades dietéticas recomendadas, em calorias, são de 80/90 calorias por kilograma de peso (Mitchell, Rynberger, Anderson \& Dibble, 1988; Menendez e cols., 1999).

Com base na magnitude deste problema, ações profiláticas devem ser implantadas. Campos, Costa e Oliveira (1998) defendem que ações profiláticas nas intoxicações são de responsabilidade do Estado, que deve criar leis e meios de controle sobre produtos novos colocados no mercado. $\mathrm{O}$ autor sugere também que os currículos escolares devem fornecer orientação sobre os riscos de produtos químicos, dos meios de produção, e devem utilizar embalagens de segurança com advertências claras sobre o uso dos produtos. Devem ser evitadas as embalagens que chamem a atenção de crianças. O maior número de intoxicações é causado por medicamentos em crianças (acidentais) e em suicidas. Portanto, deve ser realizada uma prevenção ativa de acidentes.

A ingestão de cáusticos por crianças, infelizmente, é causada por curiosidade da própria criança e por negligência e desinformação dos adultos.

\section{OBJETIVO}

O presente trabalho teve como objetivo relatar um caso de estenose de esôfago, causado por ingestão de substância ácida em uma criança de 6 anos, do sexo feminino, a qual chamaremos de "Esmeralda", e ainda relatar a experiência da criança e de sua família durante o tratamento.

\section{METODOLOGIA}

A coleta de dados foi feita através de visita domiciliar e de estudo em prontuário médico do Hospital Universitário de Maringá (HUM), na cidade de Maringá - PR, no mês de fevereiro de 2000.

\section{HISTÓRICO}

Esmeralda nasceu em São Sebastião (SP), em 27/10/93, de parto cesáreo, e foi alimentada ao seio materno. Tem um irmão com 12 anos e outro com 3 anos. A mãe estudou até a $4^{\mathrm{a}}$ série do $1^{\mathrm{o}}$ grau. O pai faleceu há 3 anos, de enfisema, e o avô tem enfisema e cardiopatia. Após a morte do marido, a mãe casou-se novamente, e o marido atual trabalha como eletricista.

Em julho de 1997, Esmeralda estava de férias na cidade de Jacarezinho (SP), quando brincava no quintal da casa e viu um saco plástico com algo semelhante a côco ralado. Colocou na boca e ingeriu soda pensando ser côco. Segundo relatos da mãe, na hora do acidente formou-se lesão descamativa de lábios e mucosa oral.

A mãe deu leite à criança e procurou o serviço de saúde daquela cidade. Após o atendimento médico foi receitada uma pomada para aplicação na mucosa oral, mas a criança foi encaminhada para sua residência. A mãe refere ter aplicado a pomada por uma semana, mas sem resultado. Esmeralda não conseguia ingerir 
alimentos sólidos via oral, mas apenas pequena quantidade de líquidos. No final da mesma semana, já em Maringá, a mãe procurou o HUM. A menina foi internada ingerindo somente leite de vaca, não conseguindo engolir outro tipo de alimento. Sentia dor intensa na deglutição, e apresentava emagrecimento (pesava 12,580 Kg). Em 25/08/97 fez dilatação esofágica, com bom resultado.

Após a primeira dilatação, foi marcada para 4/9/97 outra endoscopia, para dilatação esofágica, a qual foi realizada sem sucesso, pela impossibilidade de passar o fio guia do endoscópio. Em 5/09/97 foi realizada uma gastrostomia. Goldman (2000) afirma que a gastrostomia, um procedimento cirúrgico pouco invasivo, proporciona um máximo de benefícios ao paciente com um mínimo de riscos, podendo ser feita ambulatorialmente, com pouca dor e rápido retorno às atividades diárias.

Esmeralda foi internada pela terceira vez em 10/02/98, com diagnóstico médico de desnutrição e pneumonia, fazendo uso contínuo de antiácido (1 medida via oral 3x/dia), desde 09/97. No momento da internação apresentava tosse produtiva com secreção amarelada em grande quantidade e atrofia muscular.

A alimentação via oral foi suspensa devido ao quadro pulmonar, mas a mãe oferecia dieta via oral para Esmeralda, mesmo sendo orientada a não fazê-lo. A dieta prescrita estava sendo administrada via gastrostomia, hipercalórica e hiperprotéica, ("hiperdiet", 4 vezes ao dia). A menina referia constantemente ter vontade de ingerir alimentação via oral, e não pela gastrostomia.

Foi agendada nova endoscopia para dilatação do esôfago para 16/03, mas não foi possível realizar isto devido ao grau de estenose do esôfago, sendo necessária a sua recanalização a céu aberto. Em 20/03 perdeu-se a gastrostomia, pois o balonete da sonda furou. Foi passada, então, uma nova sonda. Em 30/03, Esmeralda recebeu alta hospitalar apresentando-se chorosa, pedindo por alimentação via oral.

Foram realizadas sucessivas dilatações esofágicas, no início de 8 em 8 dias, passando para de 15 em 15 dias, até se chegar a de 30 em 30 dias. Após as dilatações houve melhora da ingestão alimentar, conseguindo a menina ingerir alimentos como arroz, feijão, carne e pão, mas apresentou, após todas as dilatações, recidiva da estenose. Apresentou, ainda, pneumonia de repetição, e continuamente tentava ingerir alimentos via oral. A mãe, durante uma das 5 internações, incentivou a filha a ingerir alimentação via oral, mesmo a criança tendo ordem médica de não fazê-lo e ter sido orientada para assim não proceder.
O tratamento foi suspenso por falta de recursos do Sistema Único de Saúde (devido à falta de vaga para internamento), interrompendo-se as dilatações esofágicas. Em janeiro/2000, a criança, pesando $16,200 \mathrm{Kg}$, não estava conseguindo deglutir nem a própria saliva: toda a dieta estava sendo administrada via gastrostomia. Desde outubro/99 queixava-se de cefaléia frontal, que cedia a analgésicos.

Em 27/01/2000, na $5^{\text {a }}$ internação hospitalar, foi diagnosticada anemia importante com eosinofilia, tendo o peso da menina baixado para $16,000 \mathrm{Kg}$. Esmeralda não aceitou a internação. Apresentou, antes da internação, sete episódios de desmaios a qualquer hora do dia, desde o início de janeiro, sem presença de fator predisponente ou agravante. Apresentava-se emagrecida, com diminuição da força muscular em membros inferiores, dentes corroídos e gengiva com presença de mucosa cicatricial. Foi realizada duodenografia, demonstrando passagem lenta e com dificuldade pelo esôfago, com calibre bastante alterado em quase todo o trajeto.

Esmeralda foi acompanhada pelo Ambulatório do HUM, e em março/00 foi sugerido um possível encaminhamento para cirurgia pediátrica no Hospital Universitário de Londrina. A mãe recebeu instruções alimentares da nutricionista e instruções da psicóloga.

\section{RELATO DE VISITA DOMICILIAR}

A mãe relata que a Assistente Social do HUM está verificando a possibilidade de Esmeralda ir para Londrina. $\mathrm{O}$ tratamento foi interrompido há 8 meses, segundo a mãe, pois não há aparelhagem disponível no HUM, nem vaga.

$\mathrm{Na}$ primeira internação, e por estarmos fazendo estágio no HUM, reencontramos Esmeralda várias vezes. Fomos procuradas por uma tia dela na Rede Feminina de Combate ao Câncer, alegando que o hospital tinha abandonado a criança, sendo que sabíamos de toda a história anterior. Então, fomos, com mais uma voluntária da Rede, à casa de Esmeralda. A mãe não nos reconheceu em roupa civil e fora do ambiente de trabalho. Vimos que a fala da mãe não era compatível com a realidade devido às condições de saúde da menina.

Esmeralda não conseguia ingerir a própria saliva. Estava tendo acompanhamento com a nutricionista do HUM, a qual passou por escrito uma lista do que podia e não podia ingerir. Pedimos para que a mãe nos mostrasse a lista, mas esta mudou de assunto e não o fez. Ao perguntarmos se há condições financeiras para adquirir tudo o que está na lista, respondeu que nem sempre pode comprar, "mas quando o pagamento vem 
certinho dá bem". Utiliza 1 litro de leite/dia só para preparar a alimentação de Esmeralda. Faz "vitaminas" com banana, leite e outras frutas, batidas no liquiidificador; faz suco de beterraba com água. Orientamos que também poderia ser feito com leite. Diz: "não posso deixar faltar farinha láctea $e$ "mucilon" na sopa".

A mãe refere que Esmeralda faz as seguintes refeições diárias: $2 x /$ dia toma sopa, preparada com farinha láctea, leite, cenoura, chuchu, beterraba e batata. Os vegetais são cozidos e depois batidos no liqüidificador. No momento da visita, Esmeralda estava "comendo" laranja: ela colocava a laranja na boca, mastigava e cuspia no prato. A mãe disse: "ela não está com fome, mas é o dia inteiro assim, ela quer sentir o sabor, põe na boca e joga, é assim o tempo todo, já vai para três anos". Os dentes estão moles, a mãe refere que "é por causa da soda".

Perguntamos se ainda vai ao HUM. Respondeunos que fazia tempo que não ia; foi em janeiro "porque Esmeralda precisou ficar internada por causa da anemia, vou levar de novo em maio; fui conversar com a Assistente Social, aí ela disse que me avisa quando dá pra ir pra Londrina pra continuar a fazer a dilatação; doutor falou que cirurgia ela não agüenta, no último caso, precisa de UTT". Durante esta conversa, Esmeralda fala: "mãe, eu não quero ir pra UTI não, porque é só pra gente morto, eu não sou morta".

Vivemos numa sociedade que nega a morte, que não sabe o que fazer com ela e tem dificuldades de com ela conviver (Guarnieri, 1999). A criança é curiosa, quer conhecer o ambiente à sua volta, e, devido às freqüentes internações, observamos que Esmeralda convive com a morte e busca entender o que acontece ao seu redor. A autora citada afirma também que a morte é mais uma das questões que está presente na vida da criança através dos ciclos da natureza, pois ela percebe a morte de uma planta, de um animal. Estas questões não esclarecidas podem tornar-se mais complexas para a criança, trazendo-lhe muita angústia. Deste modo, dialogar com ela ajuda-a compreender o que está acontecendo e sentindo, dentro do seu entendimento e de sua percepção de mundo.

Sem dúvida, a criança tem medo da morte, do sofrimento e do afastamento da família. Ela sente e sabe da gravidade do seu estado e pede aos pais o esclarecimento e a confirmação do que está acontecendo, o que se percebe na fala de Esmeralda: "mãe, será que eu vou ficar assim até o resto da minha vida? Eu vou morrer assim, porque eu não consigo comer?".
Em relação à função intestinal, a mãe refere que o intestino de Esmeralda "funciona normal", o problema é só em relação à comida: "não passa dos $16 \mathrm{Kg}$, vamos ver se agora com o sulfato ferroso que está tomando...". Observamos a preocupação da mãe com o peso de Esmeralda, mas, por outro lado, a nossos olhos aquela não oferece os devidos cuidados à menina, o que também foi constatado pela equipe de saúde do HUM.

A mãe refere que ela dorme grande parte do tempo, com uma média de 12 horas de sono por noite. Esmeralda só dorme após a mãe se deitar com ela. Diz: "sabe porque eu acordo a minha mãe? É porque a sonda entra".

A mãe informa, por sua vez: "ela fica irritada e diz: mãe, a sonda está dentro, vem puxar". A mãe pega o material para curativo no Posto de Saúde, mas como o Posto esteve algum tempo em reforma, ela disse que às vezes comprava o soro fisiológico e a gaze; neste momento Esmeralda declara: "quero que minha mãe compre 2 soros, e coloque na sonda, pra engordar". A mãe fala: "quando estava fazendo dilatação ia a cada 15 dias no HUM, e tomava soro, é isso que ela está falando, mas não é na sonda”. Nesta visita, orientamos a mãe sobre os cuidados com a gastrostomia: curativos $1 \mathrm{x} /$ dia ou, quando necessário, com soro fisiológico e gaze estéril; lavar a sonda com $20 \mathrm{ml}$ de água após a administração da dieta ou de medicação; observar sinais de infecção na pele ao redor da inserção da sonda; administrar uma dieta sem a presença de alimentos não triturados, para evitar obstrução.

Perguntamos à mãe se quando Esmeralda fica no HUM engorda um pouco. Respondeu: " $A$ h, engorda, ela toma soro e tem uma dieta lá do hospital mesmo. Esta dieta só no hospital, não tem como comprar. $O$ irmão tem 3 anos e é fortinho e ela depois da soda ficou deste jeito...". A dieta foi fornecida pelo hospital por 8 meses e era a mãe que tomava, segundo relato da assistente social. A mãe parece estar mais preocupada com a própria saúde que com a da filha. Disse que tem trombose e que o remédio que está tomando não está resolvendo nada: "o médico falou que obstruiu a veia, fui ao benzedor e ele disse que não é, disse que é alguma coisa que pisei”. A mãe usava meias compressivas, mas refere que as tira à tarde, pois fica muito quente e "queima, queima igual fogo porque o sangue não circula direito".

Observamos até uma certa rejeição em relação à Esmeralda, comparando-a com o irmão que é saudável. O irmão mais novo está em Curitiba, com a tia, há mais de um ano, e mesmo assim a mãe de 
Esmeralda não presta a ela os cuidados necessários. Perguntamos se o HUM ainda a ajuda com algo, ao que respondeu: "não, até o remédio que usava pra fazer a dilatação dela era eu que comprava". Falou que recebeu visitas da nutricionista e da psicóloga.

Quando questionamos se Esmeralda ia à escola, a mãe respondeu: “elas não pegam, por ela estar com esta sonda e a alimentação é de 2 em 2 horas". Observamos a lacuna no desenvolvimento social da menina por não poder freqüentar as aulas devido ao seu problema de saúde, como qualquer outra criança de sua idade.

Em nenhum momento a mãe alertou-se para o fato de armazenar produtos químicos e domissanitários em locais fora do alcance das crianças, mas foi orientada por nós sobre isto, buscando prevenir futuros acidentes.

Detectamos, com base neste estudo de caso, a necessidade de acompanhamento da equipe de saúde: enfermeiro, psicólogo, médico, assistente social e nutricionista, orientando e monitorizando quanto aos cuidados específicos com a nutrição de Esmeralda, com a gastrostomia, buscando melhora da desnutrição e combate à anemia.

\section{CONSIDERAÇÕES FINAIS}

Observamos que a equipe de saúde do HUM sente-se desgastada, após orientar a mãe e saber que as orientações não foram seguidas, visto que a criança sempre adoece, apesar de a mãe dizer que sempre administra a dieta de 2 em 2 horas, existindo uma lacuna entre a realidade da criança e a da mãe. Foi feita outra visita à casa da menina. Ficamos lá por mais de 4 horas, e ela não recebeu alimentação, nem água, pela sonda, apesar de a mãe ter nos oferecido café e chá. Por essas observações, reafirmamos a importância da presença da equipe de saúde no acompanhamento domiciliar do caso, para orientar e "cobrar" os cuidados necessários à criança, a fim de melhorar seu estado de saúde. Além disso, é preciso trabalhar com Esmeralda seus vínculos familiares, prevenindo o estresse, o que Pasternak (1998) afirma ser necessário.

\section{REFERÊNCIAS BIBLIOGRÁFICAS:}

Campos, J. A., Costa, D. M. \& Oliveira, J. S. (1998). Intoxicações agudas na infância e adolescência. Em A. J. Lima (Org.). Pediatria Essencial. (pp. 803-819). São Paulo: Atheneu.

Brito Filho, D. (1988). Toxicologia humana e geral. Rio de Janeiro: Atheneu.

Broto, J., Asensio, M., Jorro, C. S., Marhuenda, C., Acosta, D., Gil Vernet, J. M., Patiño, B. \& Boix Ochoa, J. (1998). Tratamiento conservador de las estenosis cáusticas del esófago. Medicina. 4, (3), 234-237. Disponível em <http://www.bireme.br/cgi-bin.IAH2/>. (Acessado em $25 \mathrm{de}$ janeiro de 2000).

Goldman, R. K. (2000). Minimally invasive surgery. Bedside tracheostomy and gastrostomy. Crit. Care Clin. 16, (1), 113-130. Disponível em <http://www.bireme.br/cgibin/IAH2/>. (Acessado em 25 de janeiro de 2000).

Guarnieri, M. C. M. (1999). A criança também fala em morte. Pediatria Moderna. 35 (10), 837-839.

Leite, H. P. (1999). Nutrição enteral em pediatria. Pediatria Moderna. 35 (7), 457-476.

Menendez, G., Elias, M. C. \& Ito, M. T. (1999). Padrões de ingestão alimentar X crescimento. Pediatria Moderna. 35 (10), 810-812.

Mitchell, H. S., Rynberger, H. J., Anderson, L. \& Dibble, M. V. (1988). Nutrição para crianças e adolecentes. Em H. S. Mitchell (org.). Nutrição. (pp. 259-260). Rio de Janeiro: Interamericana.

Pasternak, L. (1998). Relação família, estresse e comportamento infantil, aspectos da prevenção pediátrica. Pediatria Moderna. 34 (12), 817-821.

Universidade Estadual de Maringá (1998). Relatório de atividades - 1997. Hospital Universitário Regional de Maringá. Centro de Controle de Intoxicações. Maringá.

Santos Filho, E. \& Araújo, O. R. (1997). Lesões por ingestão de cáusticos em crianças. Pediatria Moderna. 33 (4), 189194.

Schvartsman, S. (1978). Acidentes. Em: E. Marcondes (Org.). Pediatria Básica_(pp. 1195-183). São Paulo: Sarvier.

Schartsman, S. (1991). Unidade II: intoxicações por produtos químicos e de uso domiciliar. Em S. Schartsman (Org.). Intoxicações Agudas. (pp. 179-183). São Paulo: Sarvier.

Recebido em 25/05/2000

Revisado em 15/03/2001

Aceito em 30/05/2001 